Louisiana State University

LSU Digital Commons

Faculty Publications

Department of Biological Sciences

$1-1-2006$

\title{
Parenting and peer-group behavior in cultural context
}

David A. Nelson

Brigham Young University

Larry J. Nelson

Brigham Young University

Craig H. Hart

Brigham Young University

Chongming Yang

Duke University

Shenghua Jin

Beijing Normal University

Follow this and additional works at: https://digitalcommons.Isu.edu/biosci_pubs

\section{Recommended Citation}

Nelson, D., Nelson, L., Hart, C., Yang, C., \& Jin, S. (2006). Parenting and peer-group behavior in cultural context. Peer Relationships in Cultural Context, 213-246. https://doi.org/10.1017/

CB09780511499739.010

This Article is brought to you for free and open access by the Department of Biological Sciences at LSU Digital Commons. It has been accepted for inclusion in Faculty Publications by an authorized administrator of LSU Digital Commons. For more information, please contact ir@lsu.edu. 


\section{Parenting and Peer-Group Behavior in Cultural Context}

David A. Nelson

Brigham Young University - Provo, david_nelson@byu.edu

Larry J. Nelson

Criag H. Hart

Chongming Yang

Shenghua Jin

Follow this and additional works at: https://scholarsarchive.byu.edu/facpub

Part of the Other Social and Behavioral Sciences Commons

\section{BYU ScholarsArchive Citation}

Nelson, David A.; Nelson, Larry J.; Hart, Criag H.; Yang, Chongming; and Jin, Shenghua, "Parenting and Peer-Group Behavior in Cultural Context" (2006). Faculty Publications. 4570.

https://scholarsarchive.byu.edu/facpub/4570

This Book Chapter is brought to you for free and open access by BYU ScholarsArchive. It has been accepted for inclusion in Faculty Publications by an authorized administrator of BYU ScholarsArchive. For more information, please contact scholarsarchive@byu.edu, ellen_amatangelo@byu.edu. 


\title{
10 Parenting and Peer-Group Behavior in Cultural Context
}

\author{
David A. Nelson, Larry J. Nelson, Craig H. Hart, \\ Chongming Yang, and Shenghua Jin
}

Whether specific patterns of parenting are similarly associated with child peer group behavior in diverse cultural contexts has been a fascinating topic of inquiry. From classic anthropological studies dating back to the early twentieth century to the current interest in cross-cultural studies, knowledge concerning the question of universality and cultural variation in parenting linkages to childhood adjustment has expanded at an unprecedented rate (e.g., Harkness \& Super, 2002). As the general field of parenting research has uncovered distinctions in parenting styles and practices (e.g., Darling \& Steinberg, 1993; Hart, Newell, \& Olsen, 2003), these concepts have increasingly been applied to other cultures as well. Furthermore, the study of peer relationships has also increased in complexity. For example, descriptions of social behavior have evolved to represent significant subtypes of childhood aggression (e.g., physical and relational) and peer withdrawal (e.g., reticence, solitary-passive, solitary-active).

In this chapter, we highlight cultural commonalities and variations in parenting and certain child peer group behaviors that have emerged from recent studies conducted in a number of cultures around the world. For example, our own collaborative work represents cultures of Adelaide, Australia; Beijing, China; Voronezh, Russia; as well as Provo, Utah, and Baton Rouge, Louisiana (United States). As a whole, these research endeavors uniquely contribute to cross-cultural developmental science. More often than not, a relatively coherent picture regarding parenting and child outcomes is emerging from numerous cultural studies.

The structure of this chapter is as follows. The first section discusses the challenges of creating measures that are adaptable to different cultures. The problem of "imposed etics" dominates this discussion. The second section deals with specific child social behaviors and their applicability across cultures. This chapter focuses on subtypes of aggression and social withdrawal, as 
well as sociable behavior. The third section concerns parenting styles and practices. We briefly review Western research regarding various parenting styles (e.g., authoritative, authoritarian, psychologically controlling, and oversolicitous parenting) and past research suggesting that correlates of parenting are expected to be consistently related to distinct child outcomes across cultures. Finally, the measurement of indigenous parenting practices is described as a means of enriching cultural conceptions of parenting styles and practices, and suggestive data are provided.

The final section discusses universality and cultural variation in how these parenting behaviors are linked to aggressive, withdrawn, and sociable peer group behaviors. Culturally indigenous parenting practices, when relevant, are included in this summary. Research regarding parental beliefs and perceptions regarding these child behaviors is also included to provide for a more complete understanding of why parenting styles and practices might relate to child behavior. In addition, the roles that mothers and fathers may play in influencing child behavior for various cultures will be highlighted as data permits.

\section{Challenges of Cross-Cultural Research}

Considering cross-cultural patterns of parental influence on children's social development necessarily begins with the fundamental question as to whether certain patterns of child adaptive and maladaptive behaviors are identifiable and have similar meaning across cultural contexts. In prelude to a synopsis of the research, a brief summary of the challenges of cross-cultural methodology is appropriate. In attempting to apply Western psychological constructs to other cultures, researchers begin with the assumption of functional equivalence of behavioral dimensions, meaning that the behaviors in question are understood to be present and of similar psychological meaning across cultures. Given this assumption, the primary methodological concern is the emic-etic problem (Berry, 1989). Emic refers to behaviors arising from a particular culture (culture-specific), whereas etic refers to behaviors that are similar across cultures (culture-universal; Bornstein, 1991). One possible pitfall of cross-cultural research is that imposed etics may result, in which Western theoretical concepts are inappropriately imposed on other cultures. To counter accusations of an imposed etic, scholars may demonstrate various levels of measurement equivalence across cultures (Triandis, 2000).

At the most fundamental level, research instruments may be described as conceptually equivalent if they appear to be similarly understood by individuals in each cultural setting. To assure conceptual equivalence when using rating scales, it is common practice that all items in measures of interest are 
forward- and back-translated by linguists who are fluent in English (given English-speaking Western culture as a starting point) as well as the language of the culture of comparison (e.g., Chinese, Russian, Italian, etc.). Feedback is also elicited from research participants regarding the appropriateness of the translated measures. Furthermore, open-ended questions may elicit responses from study participants that are consistent with the theme of a particular parent or child behavioral construct (not originating in that culture).

Beyond these basic safeguards, a more stringent standard is required to achieve metric equivalence, in which similar psychometric properties are obtained for two sets of data from different cultures. Some structural equation modeling (SEM) modeling techniques are particularly useful in cross-cultural comparison. For example, we have adopted multisample confirmatory factor analytic techniques that can identify invariant measures of these constructs. Full invariance of measurement (where all items of interest are deemed equivalent) across cultures is often difficult to achieve, especially when comparison involves more than two cultures. In contrast, a standard of partial invariance, wherein the majority of items are statistically shown to be invariant across cultures, may be most useful (e.g., Olsen et al., 2002; Vandenberg \& Lance, 2000). One benefit of partial invariance is that items that do vary across cultures are simultaneously considered in the context of those items that are invariant. This may lead to useful hypothesizing and research regarding the cultural nuances behind a particular behavior.

\section{Subtypes of Aggression: Cross-Cultural Evidence}

Most research has examined relations between parenting and child social functioning in three broad domains: aggression, social withdrawal, and sociability. To understand these relations, it is necessary to first discuss the meaning of these behaviors in cultural context. In regard to aggression, research has expanded in conceptually significant ways in the past decade, and a number of cross-cultural studies have kept pace with these changes. The most notable contribution of recent aggression research is the identification of multiple forms of aggression. Specifically, the introduction of the construct of relational aggression has provided a point of contrast to physical aggression (Crick \& Grotpeter, 1995). Relational aggression is defined as behavior in which the perpetrator seeks to harm others through "purposeful manipulation and damage of their peer relationships" (Crick \& Grotpeter, 1995, p. 711). Similar constructs in the literature include indirect aggression (Feshbach, 1969; Lagerspetz, Björkqvist, \& Peltonen, 1988) and social aggression (Cairns et al., 1989; Galen \& Underwood, 1997; Xie et al., 2002). 
Relational aggression includes both overt (direct) and covert (indirect) forms of relational manipulation. Overt forms include the practice of purposefully excluding or avoiding another. Covert forms may include gossip and rumor-spreading, in which the source of the aggressive behavior is difficult to detect. Relational aggression is considered by peers to be mean, hurtful behavior and is associated with negative psychosocial adjustment correlates (see Crick et al., 1999, for a review). Relational aggression is most useful in that it defines patterns of aggressive behavior that are much more common than physical aggression in the peer groups of girls.

Until the advent of relational aggression, studies typically focused exclusively on physical forms of aggression, defined as a universal characteristic of human development across cultures (Coie \& Dodge, 1998). However, few studies have considered relational aggression outside of Western samples, and even studies of physical aggression have been somewhat limited in that the social meaning of such behavior in childhood (e.g., psychosocial correlates) are not well documented, especially in cultures that have only recently begun to receive empirical attention (e.g., China; see Chen, Rubin, \& Li, 1995).

An increasing number of studies have identified relational or indirect forms of aggression among children in diverse cultures. In particular, studies have shown that peers, observers, and teachers are able to reliably distinguish relational forms of aggression among preschoolers in Australia (Russell et al., 2003), Russia (Hart, Nelson et al., 1998), China (e.g., Nelson, Hart, Yang, Olsen et al., in press; Nelson, Hart, \& Yang, 2005; Yang et al., 2004), Japan (Isobe \& Sato, 2003; Hatakeyama \& Yamazaki, 2002), and the United States (Bonica et al., 2003; Crick, Casas, \& Mosher, 1997; McNeilly-Choque et al., 1996; Ostrov \& Keating, 2004; Ostrov et al., 2004; Sebanc, 2003). Researchers in Finland (e.g., Björkqvist, Lagerspetz, \& Kaukiainen, 1992; Lagerspetz et al., 1988), Italy (Tomada \& Schneider, 1997), Australia (e.g., Owens, 1996), and Indonesia (French et al., 2002) have also identified relational or indirect aggression in middle-childhood and adolescence. Relational aggression is spontaneously mentioned in descriptions of disliked peers in Indonesia, giving further credence to the idea that relational aggression is not an imposed etic, but a construct universally recognized across diverse cultures (French et al., 2002).

Beginning with playground observational work (with four- to six-year-old children) that reliably measured different forms of aggression and withdrawal (McNeilly-Choque et al., 1996; Nelson, 1996; Nelson, Robinson et al., 2005), we have developed teacher-rated and peer behavioral nomination measures. Items typical of physical and relational aggression are shown in Table 10.1 (which shows peer nomination items). Consistent with our earlier description 
Table 10.1. Items Typical of the Aggression Constructs Used in Peer Nomination Procedures

\section{Constructs and Representative Items}

Physical Aggression

Who likes to mess up or knock down other children's things?

Who grabs toys or things from other children?

Who pushes other kids out of the way to get something they want?

Who starts fights (physical) with other children?

\section{Relational Aggression}

Who won't let some of the other kids play with them, and they even might tell other kids to go away?

Who tells other kids they cannot play unless they do what everyone wants them to do? Who won't let some kids sit beside them because they don't like them?

Who tells some other kids not to be friends with someone?

Who won't listen to someone if they are mad at them (they may even cover their ears?)

of multisample confirmatory factor analysis, we have found that physical and relational aggression (as measured via teachers or peers) can be statistically distinguished in the United States, China, and Russia. In addition, most, if not all, items are found invariant and compose similar factor structures across these cultures (Nelson, Hart, Yang, \& Jin, 2005; Nelson, Hart, \& Yang, 2005).

\section{Subtypes of Withdrawal: Cross-Cultural Evidence}

Social withdrawal refers to "the consistent (across situations and time) display of all forms of solitary behavior when encountering familiar/unfamiliar peers" (Rubin, Burgess, \& Coplan, 2002, p. 330). As suggested in this definition, multiple forms of withdrawn behavior have been identified. However, unlike the study of aggression in which the same constructs (e.g., relational or physical aggression) can be studied across various ages, the subtypes of withdrawal vary according to developmental periods.

In early childhood (3-7 years of age), extensive work has been done exploring subtypes of withdrawal. Although recent work has started to examine the motivational factors (i.e., social disinterest or conflicted shyness) related to the display of withdrawn behaviors (e.g., Coplan et al., 2004), most of the extant work has focused on measuring solitary-passive, solitary-active, and reticent behaviors (Coplan et al., 1994).

Solitary-passive withdrawal is characterized by the quiet exploration of objects and constructive activities while playing alone (e.g., building with 
blocks while alone). Reticence is defined as frequent onlooking and unoccupied behaviors in both familiar and unfamiliar social contexts (e.g., wandering aimlessly, watching other children without joining in). Solitary-active behavior is characterized by solitary-functional play (repeated sensorimotor actions with or without objects, such as swinging by oneself) or by solitary dramatic/pretend play (e.g., pretending by oneself to be an animal or a machine). Solitary-active behavior differs from reticence and solitary-passive withdrawal in that it often reflects a child who has been isolated by the peer group rather than one who withdraws from the peer group.

These three forms of withdrawal have been identified among children in various cultures. For example, using our own newly developed teacher measure derived from playground observational assessments, we compared preschoolers in China, Russia, and the United States and found evidence for statistical invariance in the measurement of these constructs (Hart, Yang et al., 2000; See Table 10.2 for items). However, even though these subtypes are recognizable and measurable in each setting, it is probable that the correlates or interpretation of such behaviors may vary across cultures. For example, in Western cultures, reticence may represent a failure to exert oneself individually, whereas in Eastern cultures, it may represent a failure to conform to collectivistic group norms.

Research shows that there are significant and differential correlates of withdrawn behavior in early childhood. Studies conducted in the United States and Canada have revealed that reticence is associated with anxious-fearful and hovering behaviors, peer rejection, dysregulated emotions, and internalizing disorders (e.g., Coplan \& Rubin, 1998; Hart, DeWolf, \& Burts, 1993; Hart, Yang et al., 2000; Rubin, Coplan et al., 1995). In contrast, solitarypassive behavior is considered to be fairly benign at the beginning of early childhood (age 4). Specifically, solitary-passive behavior is positively associated with competent problem solving with peers, task persistence, performance on object-oriented tasks, and emotion regulation (Coplan et al., 1994; Coplan \& Rubin, 1998; Rubin, 1982; Rubin, Coplan et al., 1995). By ages 5 to 6 years, however, it begins to be linked to maladjustment in boys (Coplan et al., 2001). Finally, solitary-active behavior is negatively associated with adjustment (e.g., positive group interactions, perspective-taking ability, and problem-solving ability), as well as positively associated with social maladjustment, impulsivity, emotion dysregulation, and peer rejection (e.g, Coplan et al., 1994; Rubin, 1982; Rubin, Coplan et al., 1995).

Far fewer studies have been conducted examining the correlates and outcomes of these subtypes of withdrawal in other cultures. In regard to reticence, findings reflect a similar association with maladjustment across 
Table 10.2. Items Typical of the Social Withdrawal and Sociability Constructs Used in Teacher Ratings

\section{Constructs and Representative Items}

\section{Reticence}

Wanders aimlessly during free play.

Appears to be doing nothing.

Stares at other children without interacting with them.

Watches other children play without joining in.

Is fearful in approaching other children

Solitary Passive

Would rather play alone.

Does artwork by self, away from others.

Does constructive activities alone (e.g., blocks, puzzles).

Reads books alone, away from others.

Plays with toys by self rather than with other children.

\section{Solitary Active}

Pretends to be something alone (fireman, doctor, airplane) without interacting.

Does pretend/dramatic play by self.

Animates toys by self (e.g., pretends an inanimate object - doll or stick - is alive).

\section{Sociability}

Likes to talk with peers.

Makes new friends easily.

Has many friends.

Peers enjoy talking with him/her.

cultures including a link with peer rejection in China and Russia (Hart, Yang et al., 2000). Studies involving other cultures have thus far failed to reveal a connection between either solitary-passive or solitary-active behavior and psychosocial adjustment in preschoolers.

During middle-childhood and adolescence, there are fewer distinctions between forms of withdrawal. Using more global definitions of withdrawal, studies have shown that it tends to be linked to indices of maladjustment in middle-childhood and adolescence across several cultures. In the United States and Canada, withdrawal has been linked to negative self-perceptions (e.g., Hymel, Bowker, \& Woody, 1993), peer rejection (Hymel et al., 1993; Rubin, Chen, \& Hymel, 1993), victimization (Boivin, Hymel, \& Bukowski, 1995), low self-worth (Rubin, Chen et al., 1995), specific language impairment (Hart et al., 2004), and loneliness (Renshaw \& Brown, 1993; Rubin, Chen et al., 1995). Similarly, childhood withdrawal has been associated with peer rejection in Cuba, Italy, Argentina, and the Netherlands (Attili, Vermigli, 
\& Schneider, 1997; Cillessen et al., 1992; Schaughency et al., 1992; Valdivia, Schneider, Chavez, \& Chen, 2005), lower self-perceptions in Brazil, Canada, and Italy (Chen et al., 2004), loneliness in Cuba and Canada (Valdivia et al., 2005) poor test performance on individual exams (face-to-face with the teacher) in Great Britain (Crozier \& Hostettler, 2003), and long-term outcomes in Sweden, such as marrying and becoming fathers later for boys and attaining lower levels of education for girls (Kerr, Lambert, \& Bem, 1996).

The link between withdrawal and maladjustment is found even in China. It was long argued that shy, wary, and anxious behaviors may be linked to positive outcomes in China (e.g., Chen, Rubin, \& Sun, 1992; Chen et al., 1995) because these behaviors may reflect group-dependence, sensitivity, and social restraint that may be more valued in the Chinese culture (see Chen, Liu, Li, et al., 2000; Ho, 1986, Lau, 1996). However, other aspects of social withdrawal, especially social solitude and social disinterest, are often discouraged in Chinese children because of their incompatibility with the collectivistic orientation (e.g., Cheah \& Rubin, 2004; Oyserman, Coon, \& Kemmelmeier, 2002). Moreover, recent research reveals that shyness-social wariness is linked to maladjustment (e.g., peer rejection, school problems, depression), as social assertiveness and competitiveness are increasingly required in today's market-oriented China (e.g., Chen et al., 2005; Schwartz, Chang, \& Farver, 2001).

\section{Sociable Peer Group Behavior}

Compared with research on maladaptive forms of peer group behavior, less attention has been devoted to studying children's sociability in diverse cultural settings. Studies conducted in North America indicate that children who engage in friendly/amicable behavior and who are prosocial in their helping, sharing, and comforting behaviors are typically better adjusted to school, less aggressive and withdrawn, less prone to psychosocial problems, and better accepted by peers (e.g., Hart et al., 1997; Ladd \& Profilet, 1996). Sociable behavior appears to be highly adaptable in other cultural settings as well. Our recent findings, for example, suggest that preschoolers who engage in friendly-outgoing behavior are more likely to be accepted by peers in China, Russia, and the United States (Hart, Yang et al., 2000). Similar results have been obtained in China for children and youth (Chang, 2003; Chen, Dong, \& Zhou, 1997; Chen, Li et al., 2000; Chen, Liu et al., 2002). We now turn our attention to discussing parenting constructs identified across cultural settings that, as we show later, are associated with children's aggressive, withdrawn, and sociable peer group behavior in different cultures. 


\section{Culturally Relevant Parenting Constructs}

A key challenge for cross-cultural studies is to identify universal human behaviors but also to be sensitive to the impact of cultural context (Cournoyer, 2000). In regard to the first part of this goal, the majority of research studies that have assessed parenting linkages with child behavior across cultures have focused on stylistic dimensions of parenting derived from Western conceptualizations. Among the most commonly studied parenting styles across cultures are dimensions of authoritarian, authoritative, and psychologically controlling parenting (e.g., Chang et al., 2004; Chen et al., 1997; Olsen et al., 2002; Russell et al., 2003). Oversolicitous parenting, especially as it relates to child social withdrawal, is also beginning to receive cross-cultural attention.

Conceptualization of parenting styles is primarily framed in reference to parental control or demandingness as well as parental warmth and acceptance (see Maccoby \& Martin, 1983; Peterson \& Hann, 1999). Authoritative parenting, as it is commonly defined, is a mix of appropriate behavioral control (demandingness) and parental warmth. Authoritative parenting is commonly associated with competent child and adolescent outcomes in Western samples (Hart et al., 2003; Mackey, Arnold, \& Pratt, 2001; Steinberg, Darling, \& Fletcher, 1995). Dimensions of authoritative parenting typically consist of such parenting strengths as connection, reasoning-oriented regulation, and autonomy granting. Authoritarian parenting, in contrast, is defined by high levels of excessive behavioral control and lower levels of acceptance. This style is epitomized by frequent engagement in physical and verbal coercion (e.g., corporal punishment, yelling), punitiveness, and restriction of autonomy. These elements may communicate parental rejection of the child and, accordingly, is more often associated with child behavioral difficulties.

In addition, psychological control is a parenting construct that is receiving increased attention in recent research, even in cross-cultural studies (e.g., studies in Russia and China; Hart, Nelson et al., 1998; Olsen et al., 2002; Yang et al., 2004). Whereas authoritarian parenting focuses on behavioral control, psychological control is composed of stylistic dimensions reflecting a parental attack on the child's developing need for psychological autonomy (Barber, 1996, 2002; Nelson \& Crick, 2002). In contrast with behavioral control, which is needed in appropriate amounts (e.g., adequate parental monitoring, positive psychological reasoning strategies), psychological control at any level is deemed harmful to the child's individuation. Barber (1996) outlines the stylistic dimensions of psychological control in defining it as a form of control that 
“...potentially inhibits or intrudes upon psychological development through manipulation and exploitation of the parent-child bond (e.g., love withdrawal and guilt induction), negative, affect-laden expressions and criticisms (e.g., disappointment and shame), and excessive personal control (e.g., possessiveness, protectiveness)" (p. 3297).

Finally, an oversolicitous approach to parenting is one that is both excessively warm and excessively controlling (see Rubin et al., 2003; Burgess et al., 2001). These parents are overly protective and controlling to the point of being intrusive. Although these parents may often have their children's best interests in mind (i.e., safety, learning, social interaction), the constraints that oversolicitous parents place on their children may actually limit children's opportunities to practice social skills, learn how to regulate their own emotions, and build their own cognitive constructions.

In our own work, we have found similar factor structures across cultures in terms of the dimensions of parenting styles noted earlier (e.g., connection, reasoning-oriented regulation, and autonomy granting as dimensions of authoritative parenting). Factor structures of authoritative and authoritarian parenting similar to those obtained with U.S. samples have been obtained in Australia (Russell et al., 2003), China (Porter et al., in press; Wu et al., 2002), and Russia (Hart, Nelson et al., 2000). Table 10.3 provides items reflective of parenting styles used in our own work, including items representing psychologically controlling and oversolicitous parenting. These forms of parenting are also relevant across cultures, and covered in more detail later.

Given that parental acceptance/rejection is a key feature in defining the aforementioned parenting styles, Rohner's parental acceptance-rejection theory is relevant to our discussion (PARTheory; Cournoyer, 2000; Khaleque \& Rohner, 2002; Rohner 1975, 1986). This socialization theory is based on the simple hypothesis that children the world over may suffer psychologically in direct proportion to the degree they feel rejected by their parents. The universal nature of this theory is defined by an evolutionary perspective purporting the universal emotional need for positive connections to caregivers. The tenets of PARTheory have been tested in numerous studies conducted around the world, and similar results have been obtained. Accordingly, there is ample foundation for the expectation that parenting styles might be commonly associated with child maladjustment in cultures the world over. Furthermore, parenting practices, though they may be differentially emphasized across cultures, likely communicate parental acceptance or rejection and thus contribute to the overall style, or pervasive interaction climate, that is the essence of parenting styles (e.g., Darling \& Steinberg, 1993; Mize \& Pettit, 1997). 


\section{Authoritative Dimensions and Representative Items}

\section{Warmth/Acceptance (Connection)}

Gives praise when child is good.

Expresses affection by hugging, kissing, and holding child.

Tells child that we appreciate what he/she tries to accomplish.

Gives comfort and understanding when child is upset.

Shows sympathy when child is hurt or frustrated.

Aware of problems or concerns about child in school.

Encourages child to talk about his/her troubles.

\section{Reasoning/Induction (Regulation)}

Talks it over and reasons with child when misbehaving.

Encourages child to talk about consequences of behavior.

Explains the consequences of the child's behavior.

Gives the child reasons why rules should be obeyed.

\section{Democratic Participation (Autonomy Granting)}

Apologizes to child when making a mistake in parenting.

Allows child to give input into family rules.

Takes child's desires into account before asking the child to do something.

Encourages child to express himself/herself, even when disagreeing with parents.

\section{Authoritarian Dimensions and Representative Items}

\section{Physical Coercion}

Spanks when child is disobedient

Uses physical punishment as a way of disciplining child.

Slaps child when the child misbehaves.

Grabs child when he/she is being disobedient.

Guides child by physical punishment more than by reason.

\section{Verbal Hostility}

Explodes in anger towards child.

Yells or shouts when child misbehaves.

Argues with child.

\section{Nonreasoning/Punitive}

Punishes by taking privileges away with little explanation.

Punishes by putting child off with little or no justification.

When child asks why he/she has to conform, says, "Because I said so."

\section{Psychological Control Representative Items}

Becomes less friendly with our child if our child does not see things his/her way.

Makes our child feel guilty when our child does not meet our expectations.

Tells our child that we get embarrassed when he/she does not meet our expectations.

Tells our child he/she is not as good as other children.

Loses temper easily with our child.

\section{Oversolicitous Representative Items}

Readily intervenes if there is a chance that our child will fail at something.

Gets anxious when our child tries to do something new or difficult for him/her.

Feels guilty when our child does not measure up to his/her potential.

Fearful that others will not think well of my child.

Tries to control much of what our child does.

Tends to be overly involved in our child's activities 


\section{Considering Culturally Indigenous Parenting}

The aforementioned results suggest that there are elements of parenting that appear to be universal in their applicability. However, in addition to testing the relevance of Western-derived parenting style dimensions for other cultures, there is also value in attempting to establish culturally indigenous parenting measures. In particular, scholars have argued that Western parenting constructs may fail to capture important features of child-rearing in other cultures (Wu et al., 2002). Accordingly, such approaches are promising in helping to illuminate cultural nuances behind what otherwise appear to be similar behaviors and outcomes.

We draw from Chinese parenting research for illustrative purposes because this is the culture where most empirical knowledge to date on indigenous practices has been accumulated. There is already a long history of research dedicated to conceptualizing what is likely unique about Chinese parenting (Chao, 1994; Chen, 1998; Fung, 1999; Ho, 1986). Much of this stems from debates over the meaning of parental control in Chinese parenting. In particular, studies find that Chinese parents tend to be more coercive, restrictive, and controlling in their parenting styles compared with North American parents (Chiu, 1987; Leung, Lau, \& Lam, 1998; Porter et al., in press; Wu et al., 2002). A number of scholars have elaborated on the meaning of this cultural difference by suggesting that control strategies among traditional Chinese parents are uniquely indigenous and therefore qualitatively different from traditional conceptions of authoritarian parenting. Chao (1994, 2001; Chao \& Tseng, 2002), for example, has argued that what appears to be more authoritarian parenting among Chinese parents is uniquely defined by the indigenous concept of "training" (Guan Jiao in Mandarin Chinese). This form of control is purported to be demonstrative of parental involvement and concern and therefore beneficial rather than destructive to child development.

Building on these previous Chinese parenting conceptualizations, as well as focus group interviews with parents, we sought to empirically identify a number of parenting practices that were reported to define indigenous elements of Chinese parenting (Wu et al., 2002; see Table 10.4 for representative items). The first element, encouragement of modest behavior, is consistent with emphasis of group over individual accomplishments and interests. This notion is consistent with a collectivist society that favors interpersonal harmony rather than individual goals (Chen et al., 1998). Accordingly, one would expect less endorsement of this practice in parents residing in individualist cultures such as the United States. The second dimension, protection, is focused on keeping young children safely nearby and, by extension, fostering 
Table 10.4. Items Representing Culturally Indigenous Chinese Parenting Practices (Wu et al., 2002)

\section{Directiveness}

Tells our child what to do.

Demands child do things.

Scolds or criticizes when our child does not meet expectations.

\section{Protection}

Expects child to be close by when playing.

Overly worries about child getting hurt.

It is important to supervise all of our child's activities.

\section{Shaming/Love Withdrawal}

Tells child that he/she should be ashamed when misbehaving.

Tells child we get embarrassed when he/she doesn't meet our expectations.

Makes child feel guilty when our child doesn't meet our expectations.

Less friendly with our child if our child does not see things his/my way.

\section{Encouragement of Modesty}

Discourage child from expressing his/her points of view around others.

Discourage child from proudly acknowledging compliments or praise from friends or adults.

Discourage child from appearing overconfident to others about his/her abilities.

Discourage child from showing off his/her skills or knowledge to get attention.

\section{Maternal Involvement}

Mothers express love by helping children to succeed in school.

A mother's sole interest is in taking care of her children.

Children should be in the constant care of their mothers.

Mothers should do everything for their children's education.

dependency on parents for meeting the child's needs. Chinese parents are more protective than U.S. parents (Chen et al., 1998), who set a premium on independent child functioning. Third, shaming and love withdrawal are considered important mechanisms for socializing young children in China so that, "they are encouraged to act so as to maximize the positive esteem they are granted from others while trying to avoid incurring their disapproval" (Schoenhals, 1993, p. 192). Ho (1986) has reported that Chinese mothers engage in greater levels of "love-oriented" child-rearing, including love withdrawal to deal with child misbehavior, than their American counterparts. Shaming behavior that includes derogatory comments and threats of abandonment are consonant with the description of psychological control noted earlier (Fung, 1999; Wu et al., 2002). Fourth, directiveness is deemed vital for helping to correct young Chinese children's social and academic behavior in ways that promote conformity to societal expectations. This element of Chinese parenting also contrasts 
with the emphasis of U.S. parents on granting relatively greater autonomy to their children. Finally, maternal care and involvement is reflective of Chao's (1994; 2001) work, which places emphasis on Chinese mothers sacrificing significant time and energy to foster their children's academic achievement.

The primary purpose of the Wu et al. (2002) study was to empirically test whether these indigenous Chinese parenting practices might be similarly identified in both cultures (making them culture-general or culture-specific dimensions) and, if so, if they might nonetheless differ in emphasis across cultures. We expected many of these elements to be culture-general, given that parenting behaviors similar to those described earlier (e.g., maternal involvement, shaming/love withdrawal) have been identified in previous Western research. Still, these parenting dimensions may find differential application across cultures. Similarly, we sought to identify whether authoritarian and authoritative parenting styles, normally affiliated with Western parenting conceptualizations, were relevant across both cultures and might also differ across cultures.

Accordingly, Chinese mothers and American mothers were compared in their self-reported engagement in these indigenous Chinese as well as Western stylistic dimensions of parenting. Interestingly, multisample confirmatory factor analyses yielded mostly invariant factor structures for all of these dimensions of parenting across cultures, showing all indigenous Chinese parenting constructs to be empirically identifiable in the parenting of both Chinese and North American mothers. Furthermore, the indigenous constructs were relatively independent from each other as well as the authoritative and authoritarian constructs. However, with the exception of only one construct (maternal involvement), Chinese mothers reported more frequent engagement in the parenting practices considered indigenous to China. These results reinforce the notion that influence of culture is manifest in child-rearing orientations, with Chinese mothers scoring higher on most parenting dimensions considered most consistent with the collectivist foundation of their society.

As for the North American derived constructs, Chinese mothers reported lower levels of some authoritative dimensions (warmth/acceptance, autonomy granting) and higher levels of physically coercive practices that comprise an authoritarian style (cf. Porter et al., in press). The reduced emphasis on granting autonomy is expected, as it is practically the opposite of the indigenous constructs representing protection and directiveness. The contrast between lower levels of warmth and greater levels of physical coercion also appear consistent with previous research acknowledging the rather stern, straightforward approach of Chinese parents to their parental role in "training." For 
example, Chinese mothers rely on scolding and criticism to promote selfcontrol in their children (Lin \& Fu, 1990).

Nonetheless, Chinese mothers did not differ from American mothers in their reported levels of reasoning-oriented regulation (an authoritative practice) as well as verbal hostility and nonreasoning/punitive practices (authoritarian parenting). In this case, reasoning-oriented regulation seems consistent with the emphasis of the indigenous practices of protection and directiveness. In sum, we found both divergence and commonality in emphasis of these elements of parenting across these different cultural settings. The fact that all parenting dimensions were identified in both cultures is most significant, given that the "cultural distance" (i.e., differences in language, religion, socioeconomic conditions, political system, etc.) between the United States and China is noteworthy (see Triandis, 1994). These results also coincide with that of Chen and colleagues, who were the first to effectively document "Western" parenting styles among mainland Chinese parents (e.g., Chen et al., 1997; Chen, $\mathrm{Liu}, \& \mathrm{Li}, 2000)$. The next step is to examine whether these parenting constructs differentially relate to child peer-group behavior outcomes across cultures. The next section details studies of this nature.

\section{Parenting and Child Peer-Group Behavior Across Cultures}

In this section, the focus is on parenting linkages with child peer-group aggressive, withdrawn, and sociable behavior in non-Western cultures. Furthermore, we complement this emphasis with an overview of studies that describe parental beliefs and perceptions relating to these child behaviors. Unique beliefs and perceptions likely lend themselves to the patterns of more or less adaptive parenting that vary according to the individual child's levels of aggressive, withdrawn, or sociable behavior.

\section{Parental Beliefs and Perceptions Regarding Child Aggression}

Much of what parents do in seeking to socialize their children is influenced by parental beliefs and perceptions of their child's social behavior (Hart et al., 1997). It is important to understand possible cultural differences in beliefs because they provide the lens through which parenting styles and practices can be examined. If parents perceive a behavior to be harmful and yet changeable, they may respond differently than if the behavior is considered benign and unchangeable (e.g., a trait) in the culture. Similarly, given the value placed on a behavior by one's culture, parents may select a parenting approach that they believe will either reinforce or diminish a particular behavior in their children. 
When it comes to parental beliefs and perceptions regarding aggressive behavior in children, relational aggression is unexplored. In contrast, a significant number of research studies demonstrate that Western parents are genuinely concerned about physically aggressive behaviors and that beliefs regarding the source of such behavior, its modifiability, and developmental course is uniquely related to physical aggression in children (see Rubin \& Burgess, 2002, for a recent review). In particular, mothers of preschoolers who place great importance on social skills and believe that these skills can be taught are more likely to have socially competent children (Rubin, Mills, \& Rose-Krasnor, 1989) and are more involved in promoting social competence (Mize, Pettit, \& Brown, 1995). In contrast, mothers of physically aggressive children tend to see the negative behavior as an internal, unchanging attribute (Rubin et al., 1989; Coplan et al., 2002) and also believe that they have personally failed because of their own incompetence as parents (Ladd \& Le Sieur, 1995), undercutting their ability to act to assist their children in pursuing more appropriate interaction with others. They are also more likely to respond to (physically) aggressive behavior than other problematic behavior (e.g., social withdrawal) with power assertive strategies (Dodge, Pettit, \& Bates, 1994; Mills \& Rubin, 1990). Such negative reactions to aggressive behavior are understandable, given parental reports that both Western mothers and fathers feel anger, disappointment, and embarrassment when they witness their child engaging in physically aggressive behavior (Coplan et al., 2002; Mills \& Rubin, 1990, 1993; Rubin \& Mills, 1990).

Unfortunately, attention to parental beliefs and perceptions regarding aggressive behavior has been primarily an empirical focus with North American parents. Few studies exist that investigate these beliefs and perceptions in other cultures, thereby creating a context for contrast and comparison. There are a couple of notable exceptions, however. For example, Schneider et al. (1997) compared the beliefs of English Canadian and Italian mothers of seven-year-old children in regard to physically aggressive and socially withdrawn behavior. Both groups of mothers reported greater emotional reactions to aggressive rather than withdrawn behavior. However, the Italian mothers' emotional reaction was relatively subdued compared with Canadian mothers, with Italian mothers reporting less anger, embarrassment, confusion, or concern in regard to aggression. Italian mothers were also more likely to attribute physical aggression to traits within the child and reported that they would endorse high levels of power assertion to curb aggressive behavior. Finally, Italian mothers were also less likely to believe that they could help children be better accepted by peers, which appears consistent with the trait-like attribution they held for aggressive behavior. 
Another exception is the recent work of Cheah and Rubin (2004), who similarly examined European American and Mainland Chinese mothers' responses to physical aggression (externalizing behaviors) and social withdrawal in preschool children. Both American and Chinese mothers regarded aggressive behavior negatively, and both groups similarly believed aggression to be the result of situational forces rather than innate personality traits. Chinese mothers were, however, less likely to believe aggression to be stable or intentional. In regard to supervision, both sets of mothers reported greater control and firmness in dealing with aggression than withdrawal, and they believed that aggression required more directive action to curb it. Interestingly, Chinese mothers were twice as likely to endorse particular intervention strategies that dealt with training the child to act properly and correction through inductive reasoning. Chinese mothers consistently ascribed to the notion of jiao-yu, meaning to "teach [the child] the right way." This emphasis is consistent with research on Chinese parenting (Chao, 1994), which points to the importance of training.

Other cultural research findings suggest that parents in North America, China, and Russia all engage in more directive action involving the initiation and arrangement of peer contacts if their children are perceived by teachers as more aggressive or withdrawn (Hart, Yang et al., 1998). Although parental beliefs and perceptions were not directly measured in this work, these findings indicate that parents may be prone to taking remedial action that involves promoting meaningful relationships with peers when they perceive their preschool-age children to be less socially competent. Alternatively, other findings indicate less compensatory parental intervention in the face of child social incompetence, particularly when parents view difficult child behaviors as being less under their control and more difficult to socialize (Profilet \& Ladd, 1994; Rubin et al., 1989). To sort out these contradictory findings, future cultural studies should take parental beliefs and perceptions into account as moderating factors when examining associations between parenting behaviors and inept child peer-group behavior.

\section{Parenting Behaviors Linked to Child Aggression}

Parental beliefs and perceptions contribute to the establishment of particular parenting styles and practices that are the focus of this chapter. Whereas few studies have assessed parental beliefs and perceptions in cultures outside North America, a much greater number have assessed connections between parenting and child outcomes. A significant number of these studies address parental correlates of child aggression. These studies have commonly tested 
the universality of commonly found associations in North America between negative parenting styles (i.e., authoritarian, psychological control) and child behavioral problems.

Of all the non-Western cultures in which the connection between parenting styles and child outcomes has been investigated, China has received the most empirical attention. There is good reason for this, given significant theoretical debate in the last decade over the meaning of Chinese parenting. As noted earlier, proponents of the indigenous meaning of Chinese parental control (e.g., "training,") assert that Chinese children may benignly view strict or power assertive parental control as concordant with high parental expectations (Chao \& Sue, 1996). In contrast, Lau and Yeung (1996) cite evidence indicating that Chinese children, like their Western counterparts, consider controlling parenting behavior to be adverse. Hoffman (1960) long ago asserted that unqualified parental power assertion would likely evoke child hostility and opposition and, accordingly, difficulties in the child's proper internalization of control. This assertion is tested in the studies we detail here.

Some of the studies reviewed here also include attention to the significant tendency of Chinese parents to engage in psychological controlling behavior. In particular, Ho (1986) has reported that Chinese mothers are more likely than American parents to use "love-oriented" methods of discipline (e.g., love withdrawal) to deal with child misbehavior. In addition, Chinese parents engage in shaming behavior, threats of abandonment, and derogatory comments, all of which are consonant with the description of psychological control (Fung, 1999; Wu et al., 2002).

Several studies focus on the negative effect of coercive parenting in China, showing a consistent connection to children's externalizing (aggressive/disruptive) behaviors across various age groups. For example, Chen and colleagues have completed a number of studies with various age groups that find consistent connections between parenting dimensions and aggressive behavior. For example, Chen and Rubin (1994) showed that parental acceptance (as measured by Rohner's measure of parental acceptance/rejection) was negatively associated with peer and teacher ratings of aggressive behavior in Chinese fourth- and sixth-grade children. Chen et al. (1997) also found that authoritative parenting was negatively related to peer-nominated aggression in a sample of Chinese eight-year-old children. In contrast, authoritarian parenting was positively associated with aggression. Chen et al. (2001) also found similar results between parenting dimensions and observed peerdirected aggression in a sample of Chinese preschoolers. Furthermore, in a study initiated with toddlers, Chen, Wang et al. (2002) found that the child-rearing of mothers and fathers of Chinese two-year-olds was predictive 
of verbal and physical aggression in free-play episodes two years later. In particular, parental power assertion, for both mothers and fathers, was positively associated with aggression. In contrast, maternal induction and paternal warmth were negatively related to aggression. Finally, Chen, Liu, and $\mathrm{Li}$ (2000) showed that paternal warmth was negatively associated with aggressive/disruptive behavior in their young adolescents two years later. Paternal indulgence also positively predicted future aggressive/disruptive behavior.

Lei Chang and colleagues have also tested the connection between parenting styles and aggressive behavior in Chinese samples. In particular, harsh parenting on behalf of Chinese mothers and fathers was directly and indirectly (through emotional regulation) tied to child aggression in kindergarten (Chang et al., 2003). In a more recent study, Chang et al. (2004) also found harsh parenting to predict externalizing behavior in fourth-grade children in Hong Kong.

In our own work, a number of studies have identified connections between coercion as well as psychological control and aggression in Chinese preschoolers. Olsen and colleagues (2002), for example, found maternal psychological control to be linked to externalizing behaviors for Chinese boys and internalizing behavior for Chinese girls. In another study (Yang et al., 2004), we focused on connections between parental physical/verbal coercion and psychological control and aggression subtypes in Chinese preschoolers, with analyses conducted separately by parent-child dyad (both mothers and fathers were included). Using structural equation modeling to pit psychological control against coercion, we examined their associations with physical and relational aggression. Results showed that parental coercion and psychological control were associated with both forms of aggression.

Finally, Nelson, Hart, Yang, Olsen et al. (in press) used a latent sum-anddifference SEM model to assess the combined and differential contributions of Chinese mothers and fathers, in terms of their physically coercive and psychologically controlling parenting, to physical and relational aggression in preschoolers. Results showed combined parenting effects to be more prevalent than differential effects in predicting aggression. Furthermore, physical coercion predicted aggression in boys, whereas psychological control was primarily predictive of aggression in girls.

Beyond investigations in China, there are limited studies that have assessed the connection of parenting styles to child aggression in other cultures. However, a fairly consistent story is emerging among these studies. For example, our published Russian data (Hart, Nelson et al., 1998), using more traditional regression analytic approaches, reveals similar associations between 
teacher ratings of preschool children's physical and relational aggression and authoritative and authoritarian parenting. Specifically, findings indicate that less parental warmth and responsiveness, and more coercion and psychological control, are associated with greater levels of childhood relational and physical aggression.

Research in Australia also documents the relevance of parenting styles and their connection to child aggression in another Western culture. Russell and colleagues (2003) compared the parenting styles of U.S. and Australian mothers and fathers (of preschool-age children). The study also found, after controlling for child temperament, only in the case of fathers' parenting was there evidence of a link to aggression, with authoritarian parenting predicting children's physical aggression. This was true for both U.S. and Australian fathers.

Taken collectively, the findings from these studies stand in contrast to the idea that parenting styles may vary in effect by culture (Baumrind, 1996; Chao \& Tseng, 2002; Coie \& Dodge, 1998, Deater-Deckard \& Dodge, 1997; Grusec, 2002). Thus, although mean-level differences may exist across cultures, the adaptive meanings of these parenting styles appear consistent across cultures (Chen, 2000). Coercive parenting, in particular, is associated with negative outcomes in children across cultures and developmental periods. However, indigenous patterns of parenting practices have not received scrutiny in this area of research and may yield important future insights into the role of culture in the development of aggression.

\section{Parental Beliefs and Perceptions Regarding Child Withdrawal}

Across several cultures, evidence is consistent in showing that parents tend to view child withdrawal negatively. Specifically, mothers in the United States and Canada tend to (a) attribute withdrawal to internal causes, such as temperament, age, or mood; (b) react to withdrawal with anxiety, concern, disappointment, and puzzlement; and (c) respond to withdrawal by focusing on the child's present feelings with the use of low-power assertion strategies, such as information seeking, planning and providing social opportunities, or ignoring the behavior (Cheah \& Rubin, 2004; Rubin \& Mills, 1990). In examining the beliefs of both European American mothers and Chinese mothers, Cheah and Rubin (2004) noted several important similarities and distinctions. For example, in China, mothers also tend to respond to withdrawal negatively (i.e., anxiety, puzzlement, disappointment, and anger), but compared with their European American peers, they tend to attribute it to external causes (e.g., provocation, accident). Furthermore, like European American mothers, Chinese mothers focused on changing withdrawn behavior by teaching and 
persuading the child to engage in social interaction and exposing the child to social situations. However, Chinese mothers said they would use these strategies with the intent to teach the child to know how to act appropriately in similar situations in the future (in contrast with European American mothers, who intended to deal with the child's needs in that moment).

Similar studies have been conducted in other cultures as well. Compared with English Canadian mothers, Italian mothers felt lower levels of guilt and concern when presented with hypothetical scenarios of withdrawal and attributed the behavior to a trait in a child that could not be changed (Schneider et al., 1997). Schneider and colleagues hypothesized that the lack of concern regarding children's peer relationships in Italy may stem from Italian families favoring a strong connection with extended family rather than peers. In another study by Cheah and Park (2005) Korean mothers reacted to scenarios of social withdrawal. These mothers reacted with negative emotions (e.g., puzzled, disappointed, anxious, and angry) to social withdrawal and favored lower-powered/indirect strategies (e.g., creating opportunities for the child to play with others to practice their skills) as ways to achieve social-centered goals (e.g., helping children to get along well with others, improving their interactions with peers, and developing their general social competence or comfort in social situations).

\section{Parenting Behaviors Linked to Child Withdrawal}

Researchers have found several important links between parenting and fearful, inhibited, and withdrawn behaviors in children in Western cultures. Most notably, emerging evidence suggests that an oversolicitous style of parenting (i.e., overly protective/controlling, intrusive behavior) is linked to children's social withdrawal. For example, Rubin, Burgess, and Hastings (2002) found that mothers of inhibited toddlers (aged two) who engaged in intrusive parenting behaviors (e.g., unsolicited intervention) had children who engaged in high amounts of reticent/wary behavior at age four. There was no relation between age-two inhibition and age-four reticence for children whose mothers were not intrusive. Similarly, Rubin et al. (1999) found that parental perceptions of child shyness/social wariness at age two predicted both mothers' and fathers' expressed lack of encouragement of independence. Indicative of European American mothers' goal to focus on the child's immediate needs (Cheah \& Rubin, 2004), these studies suggest that some parents may respond to perceived wariness in their children with parental behaviors (i.e., intrusive, overprotective parenting) that actually exacerbate the problem by not allowing children opportunities to develop regulatory and coping skills to deal with their social anxieties in future social settings. 
Emerging work in China is beginning to look at the linkages between parenting and withdrawal. In one of the first studies examining these associations in China using a sample of toddlers and their parents, Chen and colleagues found a positive relation between inhibition and parental acceptance and encouragement of achievement, and a negative correlation with parental control (Chen et al., 1998). Although these findings may reflect a link between "positive" parenting and inhibition, emerging evidence suggests a different picture once children enter early childhood. In our own work (Nelson, Hart, Wu et al., in press), we have begun to examine many of the indigenous practices noted earlier in the Wu et al. (2002) study (i.e., encouragement of modest behavior, protection, shaming, directiveness) that, when overemphasized, were hypothesized to be tied to children's withdrawn behaviors (i.e., reticence, solitary-passive withdrawal, solitary-active behavior). Overemphasis of protection, for example, included items such as "readily intervenes if there is a chance that our child will fail at something." Engagement in coercive behavior was also considered in this study.

In particular, we expected that parenting practices that limited children's opportunities to practice social skills and regulate their own emotions (i.e., maternal overprotection, directiveness, and coercion) or punished "wrong" behaviors (i.e., shaming and coercion) would be positively associated with socially fearful and incompetent (i.e., immature and impulsive) behaviors (i.e., reticent and solitary-active behaviors). Conversely, because parents may want to foster behaviors conducive to academic performance (i.e., solitarypassive behavior) and social acceptance (modesty - not appearing proud or overconfident), they may use shaming or modesty encouragement to motivate children to engage in these behaviors.

Chinese mothers' self-reports of indigenous parenting were correlated with teacher ratings of child behavior. Results showed that maternal directiveness was linked to reticent behavior in girls. Furthermore, maternal overprotection was positively related to solitary-passive behavior, reticence, and modesty in girls. For girls, maternal coercion was positively associated with solitaryactive and reticent behavior. Finally, maternal shaming was positively related to all forms of withdrawn behaviors in boys and girls, as well as modest behavior in boys.

Taken together, these findings identify links between parenting practices and social withdrawal in China that are largely consistent with findings in Western cultures such as the United States. Collectively, the literature is beginning to show that parents tend to perceive shy, fearful behaviors as problematic in cultures that promote self-sufficiency and individualism (e.g., United States, Canada) as well as in collectivist cultures that promote group 
harmony (e.g., China, Korea). Furthermore, parenting that limits children's opportunities to practice social skills and regulate their own emotions tends to be linked to fearful and immature forms of withdrawal across most of the cultures that have been studied to this point.

\section{Parental Beliefs and Perceptions Regarding Child Sociability}

The cross-cultural literature on parenting and peer sociability is more limited than studies of parenting and childhood aggression and withdrawal. This is especially the case in regard to relevant parental beliefs and perceptions. Findings of Western studies support the notion that parents who empower children with the abilities to initiate, communicate, and manage their own peer relationships are more likely to have children who are more sociable with peers. However, this type of parental management appears to be more likely in cases where parents perceive their children as being more outgoing and sociable to begin with (Profilet \& Ladd, 1994) and who believe more strongly that informal peer-play activities are important to children's development (Ladd \& Hart, 1992). Thus, more research is necessary to understand cultural nuances in parental beliefs and the ways that parents perceive child sociability and promote childhood interactions with peers through specific parenting practices.

\section{Parenting Behaviors Linked to Child Sociability}

Research focusing on parenting practices in North America suggests that mothers who actively orchestrate peer-group experiences are more likely to have preschool children who have a larger number of playmates and more consistent play companions (Ladd \& Golter, 1988). Parental peer-group initiations have also been associated with more sociable behavior with peers in preschool classrooms (Ladd \& Hart, 1992) and to greater classroom peer acceptance, particularly for boys (Ladd \& Golter, 1988; Ladd \& Hart, 1992). Further evidence suggests that parents who verbally coach their children about how to extend invitations to play have children who initiate more of their own play dates (Ladd \& Hart, 1992). Similar findings have been obtained for German grade-schoolers, with children engaging in closer, more stable friendships with peers if their parents actively arrange and stimulate peer contacts (Krappman, 1989). In our cross-cultural work, connections between parental initiation of their children's peer contacts and teacher-rated child sociability have been replicated in Voronezh, Russia, but not in other cultural samples including Beijing, China (Hart, Yang et al., 1998). 
Beyond direct parenting effects on peer sociability, indirect effects, through the vehicle of parenting styles, are also notable. Although numerous North American studies have been conducted that show linkages between more authoritative and less authoritarian parenting styles and sociable child peergroup behavior (see Hart et al., 2003 for a review), few studies of this nature have been conducted in other cultural settings. One exception is a recent study by Russell et al. (2003), which examined how parenting patterns in Australia and the United States might be associated with preschoolers' sociable behavior. Consistent with arguments that parenting can have different consequences for child development depending on child characteristics, authoritarian parenting appeared to diminish sociable peer-group behavior for children who were rated lower (rather than higher) on temperamental qualities that reflect outgoing traits. In another notable study of nine and twelve-year-old children in mainland China, parental acceptance as indexed by items such as "I talk to my child in a warm and affectionate way" was associated with socially competent behavior in school (Chen \& Rubin, 1994). Similar findings linking more authoritative and less authoritarian parenting with child peer group sociability have also been obtained in other Chinese samples. (e.g., Chen et al., 1997; Chen, Liu, \& Li, 2000). Beyond this, little is known about how parenting styles and practices can facilitate or diminish sociable child behavior with peers in diverse cultural settings.

\section{Conclusion}

In conclusion, based on data we have reviewed, it would appear that many of the child behavioral orientations and stylistic patterns and practices of parenting that have been identified in North American cultural contexts are empirically identifiable in and are applicable to many non-Western cultural contexts. Culturally indigenous parenting practices are also worthy of study and are thus far consistent with the notion that certain practices may be more heavily emphasized in particular cultures. However, the Wu et al. (2002) study also shows that practices considered indigenous to China are also readily identifiable in the U.S. culture. This finding suggests that parents may hold much in common, even across significant cultural distances.

Furthermore, there are also significant similarities in the beliefs and perceptions of parents across cultures when it comes to the behaviors of interest here. These beliefs naturally tie in with parenting dimensions, which are consistently associated with aggression, social withdrawal, and sociability across cultures studied to date. Accordingly, as Chen (2000) has observed in regard to United States-China comparisons, findings regarding the correlates 
of parenting styles suggest that the adaptive meanings of parenting styles are consistent across these cultures.

As noted earlier in regard to PARTheory, parental acceptance (warmth) appears to be a defining dimension of parenting across cultures. MacDonald (1992) has also argued that warmth is a unique dimension of parenting that has evolved as a mechanism for promoting cohesive family relationships and paternal investment in child-rearing. Warmth also facilitates compliance and assimilation of adult values in child offspring. Thus, the continuum between warmth and coldness in family relationships is a "pan-human phenomenon" (p. 754). Nonetheless, patterns of warmth vary significantly within as well as across cultures and consistently correlate with more or less adaptive functioning. Accordingly, differences in mean levels of parenting behaviors across cultures warrants more detailed study, especially in regard to how these mean differences may lead to unique child outcomes or greater prevalence of particular social behaviors, relatively speaking, within cultures.

Though much good research has been completed in this domain, our impression is that cross-cultural science has yet to mature. In particular, there are several limitations of the comparative research currently assembled. Studies are often composed of limited samples and are not fully representative of the diversity that is often found within each culture that has been covered here. For example, our Chinese data represent an urban sample of well-educated parents in Beijing, China, which is hardly representative of the diversity of populations found in the whole of China (with substantial differences across cities and regions by ethnicity, socioeconomic status levels, education levels, and rural versus urban environments). Furthermore, though a significant number of non-Western cultures have yielded important data consistent with the theme of this chapter, there are still many cultures around the world that have not yet been explored. Accordingly, it is premature to state that connections between parenting and child peer-group behavior that are thus far consistent across cultures will remain so in future work. Studies may yet emerge that define elements of parenting or child social behavior that are truly unique because of cultural influences. In sum, cross-cultural comparative study of parenting and child behavior has already produced a significant number of important studies, and this field will continue to provide opportunities for significant research for decades to come.

\section{Acknowledgments}

Portions of this chapter were presented in M. Bornstein and M. L. Siedl de Moura (Chairs), Multicultural studies of social development in early life 
at the XVIIIth biennial meetings of the International Society for the Study of Behavioural Development, held in Ghent, Belgium. Funding for Brigham Young University (BYU) research reported in this chapter was provided by the College of Family, Home, and Social Sciences, the Camilla Eyring Kimball Endowment, the BYU Family Studies Center, and the Zina Young Williams Card Professorship awarded to Craig H. Hart.

\section{References}

Attili, G., Vermigli, P., \& Schneider, B. (1997). Peer acceptance and friendship patterns among Italian schoolchildren within a cross-cultural perspective. International Journal of Behavioral Development, 21, 277-288.

Barber, B. K. (1996). Parental psychological control: Revisiting a neglected construct. Child Development, 67, 3296-3319.

Barber, B. K. (Ed). (2002). Intrusive parenting: How psychological control affects children and adolescents. Washington, DC: American Psychological Association.

Baumrind, D. (1996). The discipline controversy revisited. Family Relations, 45, 405414.

Berry, J. W. (1989). Imposed etics-emics-derived etics: The operationalization of a compelling idea. International Journal of Psychology, 24, 721-735.

Björkqvist, K., Lagerspetz, K. M. J., \& Kaukiainen, A. (1992). Do girls manipulate and boys fight? Developmental trends in regard to direct and indirect aggression. Aggressive Behavior, 18, 117-127.

Boivin, M., Hymel, S., \& Bukowski, W. M. (1995). The roles of social withdrawal, peer rejection, and victimization by peers in predicting loneliness and depressed mood in childhood. Development and Psychopathology, 7, 765-785.

Bonica, C., Arnold, D. H., Fisher, P. H., Zeljo, A., \& Yershova, K. (2003). Relational aggression, relational victimization, and language development in preschoolers. Social Development, 12, 551-562.

Bornstein, M. H. (Ed.). (1991). Cultural approaches to parenting. Hillsdale, NJ: Lawrence Erlbaum Associates.

Burgess, K. B., Rubin, K. H., Chea, C. S. L., \& Nelson, L. J. (2001). Behavioral inhibition, social withdrawal, and parenting. In L. E. Alden \& W. R. Crozier (Eds.), International handbook of social anxiety: Concepts, research and interventions relating to the self and shyness. (pp.137-158). New York: Wiley.

Cairns, R. B., Cairns, B. D., Neckerman, H. J., Ferguson, L. L., \& Gariepy, J. L. (1989). Growth and aggression: I. Childhood to early adolescence. Developmental Psychology, 25, 320-330.

Chang, L. (2003). Variable effects of children's aggression, social withdrawal, and prosocial leadership as functions of teacher beliefs and behaviors. Child Development, 74, $535-548$.

Chang, L., Lansford, J. E., Schwartz, D., \& Farver, J. M. (2004). Marital quality, maternal depressed affect, harsh parenting, and child externalizing in Hong Kong Chinese families. International Journal of Behavioral Development, 28, 311318. 
Chang, L., Schwartz, D., Dodge, K. A., \& McBride-Chang, C. (2003). Harsh parenting in relation to child emotion regulation and aggression. Journal of Family Psychology, 17, 598-606.

Chao, R. K. (1994). Beyond parental control and authoritarian parenting style: Understanding Chinese parenting through the cultural notion of training. Child Development, 65, 1111-1119.

Chao, R. K. (2001). Extending research on the consequences of parenting style for Chinese Americans and European Americans. Child Development, 72, 1832 1843.

Chao, R. K., \& Sue, S. (1996). Chinese parental influence and their children's school success: A paradox in the literature on parenting styles. In S. Lau (Ed.), Growing up the Chinese way (pp. 93-120). Hong Kong: The Chinese University Press.

Chao, R. K., \& Tseng, V. (2002). Parenting of Asians. In M. H. Bornstein (Ed.), Handbook of parenting: Volume 4. Social conditions and applied parenting (pp. 59-93). Mahwah, NJ: Lawrence Erlbaum Associates.

Cheah, C. S. L., \& Park, S. (2005). South Korean mothers' beliefs regarding aggression and social withdrawal in preschoolers. Manuscript submitted for publication.

Cheah, C. S. L., \& Rubin, K. H. (2004). European American and mainland Chinese mothers' responses to aggression and social withdrawal in preschoolers. International Journal of Behavioral Development, 28, 83-94.

Chen, X. (1998). The changing Chinese family: Resources, parenting practices, and children's social-emotional problems. In U. P. Gielen \& A. L. Comunian (Eds.), Family and family therapy in international perspective. (pp. 150-167). Trieste, Italy: Edizioni LINT.

Chen, X. (2000). Growing up in a collectivistic culture: Socialization and socioemotional development in Chinese children. In U. P. Gielen \& A. L. Comunian (Eds.), International perspectives on human development (pp. 213-232). Lengerich, Germany: Pabst Science.

Chen, X., Cen, G., Li, D., \& He, Y. (2005). Social functioning and adjustment in Chinese children: The imprint of historical time. Child Development, 76, 182-195.

Chen, X., Dong, Q., \& Zhou, H. (1997). Authoritative and authoritarian parenting practices and social and school performance in Chinese children. International Journal of Behavioral Development, 21, 855-873.

Chen, X., Hastings, P. D., Rubin, K. H., Chen, H., Cen, G., \& Stewart, S. L. (1998). Child-rearing attitudes and behavioral inhibition in Chinese and Canadian toddlers: A cross-cultural study. Developmental Psychology, 34, 677-686.

Chen, X., Li, D., Li, Z., Li, B., \& Liu, M. (2000). Sociable and prosocial dimensions of social competence in Chinese children: Common and unique contributions to social, academic, and psychological adjustment. Developmental Psychology, 36, 302-314.

Chen, X., Liu, M., \& Li, D. (2000). Parental warmth, control, and indulgence and their relations to adjustment in Chinese children: A longitudinal study. Journal of Family Psychology, 14, 401-419.

Chen, X., Liu, M., Li, B., Cen, G., Chen, H., \& Wang, L. (2000). Maternal authoritative and authoritarian attitudes and mother-child interactions and relationships in urban China. International Journal of Behavioral Development, 24, 119-126.

Chen, X., Liu, M., Rubin, K. H., Cen, G., Gao, Z., \& Li, D. (2002). Sociability and prosocial orientation as predictors of youth adjustment: A seven-year longitudinal 
study in a Chinese sample. International Journal of Behavioral Development, 26, $128-136$.

Chen, X., \& Rubin, K. H. (1994). Family conditions, parental acceptance, and social competence and aggression in Chinese children. Social Development, 3, 269290.

Chen, X., Rubin, K. H., \& Li, B. (1995). Social and school adjustment of shy and aggressive children in China. Development and Psychopathology, 7, 337-349.

Chen, X., Rubin, K. H., \& Sun, Y. (1992). Social reputation and peer relationships in Chinese and Canadian children: A cross-cultural study. Child Development, 63, 1336-1343.

Chen, X., Wang, L., Chen, H., \& Liu, M. (2002). Noncompliance and child-rearing attitudes as predictors of aggressive behavior: A longitudinal study of Chinese children. International Journal of Behavioral Development, 26, 225-233.

Chen, X., Wu, H., Chen, H., Wang, L., \& Cen, G. (2001). Parental affect, guidance, and power assertion and aggressive behavior in Chinese children. Parenting: Science and Practice, 1, 159-183.

Chen, X., Zappulla, C., Coco, A. L., Schneider, B., Kaspar, V., De Oliveira, A. M., et al. (2004). Self-perceptions of competence in Brazilian, Canadian, Chinese and Italian children: Relations with social and school adjustment. International Journal of Behavioral Development, 28, 129-138.

Chiu, L. H. (1987). Child-rearing attitudes of Chinese, Chinese-American, and AngloAmerican mothers. International Journal of Psychology, 22, 409-419.

Cillessen, A. H., Van IJzendoorn, H. W., Van Lieshout, C. F., \& Hartup, W. W. (1992). Heterogeneity among peer-rejected boys: Subtypes and stabilities. Child Development, 63, 893-905.

Coie, J. D., \& Dodge, K. A. (1998). Aggression and antisocial behavior. In W. Damon (Series Ed.) \& N. Eisenberg (Vol. Ed.), Handbook of child psychology: Vol. 3. Social, emotional and personality development (pp. 779-862). New York: Wiley.

Coplan, R. J., Hastings, P. D., Lagace-Seguin, D. G., \& Moulton, C. E. (2002). Authoritative and authoritarian mothers' parenting goals, attributions, and emotions across different childrearing contexts. Parenting: Science and Practice, 2, 1-26.

Coplan, R. J., Molina, M. G., Lagace-Seguin, D. G., \& Wichmann, C. (2001). When girls versus boys play alone: Gender differences in the relations between nonsocial play and adjustment in kindergarten. Developmental Psychology, 37, 464-474.

Coplan, R. J., Prakash, K., O’Neil, K., \& Armer, M. (2004). Do you "want" to play? Distinguishing between conflicted shyness and social disinterest in early childhood. Developmental Psychology, 40, 244-258.

Coplan, R. J., \& Rubin, K. H. (1998). Exploring and assessing nonsocial play in the preschool: The development and validation of the Preschool Play Behavior Scale. Social Development, 7, 72-91.

Coplan, R. J., Rubin, K. H., Fox, N. A., Calkins, S. D., \& Stewart, S. L. (1994). Being alone, playing alone, and acting alone: Distinguishing among reticence and passive and active solitude in young children. Child Development, 65, 129-137.

Cournoyer, D. E. (2000). Universalist research: Examples drawn from the methods and findings of parental acceptance-rejection theory. In U. P. Gielen \& A. L. Comunian (Eds.), International perspectives on human development (pp. 213-232). Lengerich, Germany: Pabst Science. 
Crick, N. R., Casas, J. F., \& Mosher, M. (1997). Relational and overt aggression in preschool. Developmental Psychology, 33, 579-588.

Crick, N. R., \& Grotpeter, J. K. (1995). Relational aggression, gender, and socialpsychological adjustment. Child Development, 66, 710-722.

Crick, N., Werner, N. E., Casas, J. F., O’Brien, K. M., Nelson, D. A., Grotpeter, J. K., et al. (1999). Childhood aggression and gender: A new look at an old problem. In D. Bernstein (Ed.), Volume 45 of the Nebraska symposium on motivation: Gender and motivation (pp. 75-141). Lincoln: University of Nebraska Press.

Crozier, W. R., \& Hostettler, K. (2003). The influence of shyness on children's test performance. British Journal of Educational Psychology, 73, 317-328.

Darling, N., \& Steinberg, L. (1993). Parenting style as context: An integrative model. Psychological Bulletin, 113, 487-496.

Deater-Deckard, K., \& Dodge, K. A. (1997). Externalizing behavior problems and discipline revisited: Nonlinear effects and variation by culture, context, and gender. Psychological Inquiry, 8, 161-175.

Dodge, K. A., Pettit, G. S., \& Bates, J. E. (1994). Socialization mediators of the relation between socioeconomic status and child conduct problems. Child Development, 65, 649-665.

Feshbach, N. D. (1969). Sex differences in children's modes of aggressive responses toward outsiders. Merrill-Palmer Quarterly, 15, 249-258.

French, D. C., Jansen, E. A., \& Pidada, S. (2002). United States and Indonesian children's and adolescents' reports of relational aggression by disliked peers. Child Development, 73, 1143-1150.

Fung, H. (1999). Becoming a moral child: The socialization of shame among young Chinese children. Ethos, 27, 180-209.

Galen, B. R., \& Underwood, M. K. (1997). A developmental investigation of social aggression among children. Developmental Psychology, 33(4), 589-600.

Grusec, J. E. (2002). Parental socialization and the acquisition of values. In M. H. Bornstein (Ed.), Handbook of parenting: Volume 5. Practical issues in parenting (pp. 143-167). Mahwah, NJ: Lawrence Erlbaum Associates.

Harkness, S., \& Super, C. M. (2002). Culture and parenting. In M. H. Bornstein (Ed.), Handbook of parenting: Vol. 2. Biology and ecology of parenting (pp. 253-280). Mahwah, NJ: Lawrence Erlbaum Associates.

Hart, C. H., DeWolf, M. D., \& Burts, D. C. (1993). Parental discipline strategies and preschoolers' play behavior in playground settings. In C. H. Hart (Ed.), Children on playgrounds: Research perspectives and applications (pp. 271-313). Albany: State University of New York Press.

Hart, C. H., Nelson, D. A., Robinson, C. C., Olsen, S. F., \& McNeilly-Choque, M. K. (1998). Overt and relational aggression in Russian nursery-school-age children: Parenting style and marital linkages. Developmental Psychology, 34, 687-697.

Hart, C. H., Nelson, D. A., Robinson, C. C., Olsen, S. F., \& McNeilly-Choque, M. K., \& McKee, T. R. (2000). Russian parenting styles and family processes: Linkages with subtypes of victimization and aggression. In K. A. Kerns, J. M. Contreras, \& A. M. Neal-Barnett (Eds.), Family and peers: Linking two social worlds (pp. 47-84). Westport, CT: Praeger.

Hart, C. H., Newell, L. D., \& Olsen, S. F. (2003). Parenting skills and social/ communicative competence in childhood. In J. O. Greene \& B. R. Burleson (Eds.), 
Handbook of communication and social interaction skill (pp. 753-797). Mahwah, NJ: Lawrence Erlbaum Associates.

Hart, C. H., Olsen, S. F., Robinson, C. C., \& Mandleco, B. L. (1997). The development of social and communicative competence in childhood: Review and a model of personal, familial, and extrafamilial processes. In B. R. Burleson (Ed.), Communication yearbook 20 (pp. 305-373). Thousand Oaks, CA: Sage.

Hart, C. H., Yang, C., Nelson, D. A., Jin, S., Bazarskaya, N., Nelson, L. J., et al. (1998). Peer contact patterns, parenting practices, and preschoolers' social competence in China, Russia, and the United States. In P. Slee \& K. Rigby (Eds.), Children's peer relations (pp. 3-30). London: Routledge.

Hart, C. H., Yang, C., Nelson, L. J., Robinson, C. C., Olsen, J. A., Nelson, D. A., et al. (2000). Peer acceptance in early childhood and subtypes of socially withdrawn behavior in China, Russia, and the United States. International Journal of Behavioral Development, 24, 73-81.

Hart, K. I., Fujiki, M., Brinton, B., \& Hart, C. H. (2004). The relationship between social behavior and severity of language impairment. Journal of Speech, Language, and Hearing Research, 47, 647-662.

Hatakeyama, M., \& Yamazaki, A. (2002). An observational study of preschooler's aggressive behavior in free play, in relation to gender and peer group status. The Japanese Journal of Developmental Psychology, 13(3), 252-260.

Ho, D. Y. F. (1986). Chinese pattern of socialization: A critical review. In M. H. Bond (Ed.), The psychology of the Chinese people (pp. 1-37). Oxford, England: Oxford University Press.

Hoffman, M. L. (1960). Power assertion by the parent and its impact on the child. Child Development, 31, 129-143.

Hymel, S., Bowker, A., \& Woody, E. (1993). Aggressive versus withdrawn unpopular children: Variations in peer and self perceptions in multiple domains. Child Development, 64, 879-896.

Isobe, M., \& Sato, S. (2003). Relational aggression and social skills of preschool children. Japanese Journal of Educational Psychology, 51, 13-21.

Kerr, M., Lambert, W. W., \& Bem, D. J. (1996). Life course sequelae of childhood shyness in Sweden: Comparison with the United States. Developmental Psychology, 32, 1100-1105.

Khaleque, A., \& Rohner, R. P. (2002). Perceived parental acceptance-rejection and psychological adjustment: A meta-analysis of cross-cultural and intracultural studies. Journal of Marriage and Family, 64, 54-64.

Krappman, L. (1989). Family relationships and peer relationships in middle childhood. In K. Kreppner \& R. M. Lerner (Eds.), Family systems and life-span development (pp. 93-104). Hillsdale, NJ: Lawrence Erlbaum Associates.

Ladd, G. W., \& Golter, B. (1988). Parents' management of preschoolers' peer relations: Is it related to children's social competence? Developmental Psychology, 24, 109-117.

Ladd, G. W., \& Hart, C. H. (1992). Creating informal play opportunities: Are parents' and preschoolers' initiations related to children's competence with peers? Developmental Psychology, 28, 1179-1187.

Ladd, G. W., \& Le Sieur, K. D. (1995). Parents and children's peer relationships. In M. H. Bornstein (Ed.), Handbook of parenting: Vol. 4. Applied and practical parenting (pp. 377-410). Hillsdale, NJ: Lawrence Erlbaum Associates. 
Ladd, G. W., \& Profilet, S. M. (1996). The Child Behavior Scale: A teacher-report measure of young children's aggressive, withdrawn, and prosocial behaviors. Developmental Psychology, 32, 1008-1024.

Lagerspetz, K. M. J., Björkqvist, K., \& Peltonen, T. (1988). Is indirect aggression typical of females? Gender differences in aggressiveness in 11- to 12-year-old children. Aggressive Behavior, 14, 403-414.

Lau, S. (1996). Growing up the Chinese way: Chinese child and adolescent development. Hong Kong: The Chinese University Press.

Lau, S., \& Yeung, P. P. W. (1996). Understanding Chinese child development: The role of culture in socialization. In S. Lau (Ed.), Growing up the Chinese way (pp. 29-44). Hong Kong: The Chinese University Press.

Leung, K., Lau, S., \& Lam, W. (1998). Parenting styles and academic achievement: A cross-cultural study. Merrill-Palmer Quarterly, 44, 157-172.

Lin, C. C., \& Fu, V. R. (1990). A comparison of child-rearing practices among Chinese, immigrant Chinese, Caucasian-American parents. Child Development, 61, 429-433.

Maccoby, E. E., \& Martin, J. A. (1983). Socialization in the context of the family: Parent-child interaction. In E. M. Hetherington (Ed.) \& P. H. Mussen (Series Ed.), Handbook of child psychology (pp. 1-102). New York: Wiley.

MacDonald, K. (1992). Warmth as a developmental construct: An evolutionary analysis. Child Development, 63, 753-773.

Mackey, K., Arnold, M. L., \& Pratt, M. W. (2001). Adolescents' stories of decision making in more and less authoritative families: Representing the voices of parents in narrative. Journal of Adolescent Research, 16, 243-268.

McNeilly-Choque, M. K., Hart, C. H., Robinson, C. C., Nelson, L. J., \& Olsen, S. F. (1996). Overt and relational aggression on the playground: Correspondence among different informants. Journal of Research in Childhood Education, 11, 47-67.

Mills, R. S. L., \& Rubin, K. H. (1990). Parental beliefs about problematic social behaviors in early childhood. Child Development, 61, 138-151.

Mills, R. S. L., \& Rubin, K. H. (1993). Socialization factors in the development of social withdrawal. In K. H. Rubin \& J. B. Asendorpf (Eds.), Social withdrawal, inhibition, and shyness in childhood (pp. 117-148). Hillsdale, NJ: Lawrence Erlbaum Associates.

Mize, J., \& Pettit, G. S. (1997). Mothers' social coaching, mother-child relationship style, and children's peer competence: Is the medium the message? Child Development, 68 , 312-332.

Mize, J., Pettit, G. S., \& Brown, G. (1995). Mothers' supervision of their children's play: Relations with beliefs, perceptions, and knowledge. Developmental Psychology, 31, 311-321.

Nelson, D. A., \& Crick, N. R. (2002). Parental psychological control: Implications for childhood physical and relational aggression. In B. K. Barber (Ed.), Intrusive parenting: How psychological control affects children and adolescents (pp. 168-189). Washington, DC: American Psychological Association.

Nelson, D. A., Hart, C. H., \& Yang, C. (2005). Russian and U.S. comparative data regarding physical and relational aggression: Temperament and peer status linkages. Manuscript in preparation.

Nelson, D. A., Hart, C. H., Yang, C., Olsen, J. A., \& Jin, S. (in press). Aversive parenting in China: Associations with child physical and relational aggression. Child Development. 
Nelson, D. A., Hart, C. H., Yang, C., \& Jin S. (2005). Aggression subtypes in U.S. and Chinese preschoolers: Cultural equivalence, statistical distinctiveness, and peer outcomes. Manuscript submitted for publication.

Nelson, D. A., Robinson, C. C., \& Hart, C. H. (2005). Relational and physical aggression of preschool-age children: Peer status linkages across informants. Early Education \& Development, 16, 115-139.

Nelson, L. J. (1996). Relations between sociometric status and three subtypes of withdrawn behavior in preschool children: A multi-method perspective. Unpublished master's thesis, Brigham Young University, Provo, Utah.

Nelson, L. J., Hart, C. H., Wu, B., Yang, C., \& Olsen, S. (in press). Relations between Chinese mothers' parenting practices and social withdrawal in early childhood. International Journal of Behavioral Development.

Olsen, S. F., Yang, C., Hart, C. H., Robinson, C. C., Wu, P., Nelson, D. A., et al. (2002). Maternal psychological control and preschool children's behavioral outcomes in China, Russia, and the United States. In B. K. Barber (Ed.), Intrusive parenting: How psychological control affects children and adolescents (pp. 235-262). Washington DC, American Psychological Association.

Ostrov, J. M., \& Keating, C. F. (2004). Gender differences in preschool aggression during free play and structured interactions: An observational study. Social Development, 13, 255-277.

Ostrov, J. M., Woods, K. E., Jansen, E. A., Casas, J. F., \& Crick, N. R. (2004). An observational study of delivered and received aggression, gender, and social-psychological adjustment in preschool: “This White Crayon Doesn't Work...." Early Childhood Research Quarterly, 19, 355-371.

Owens, L. D. (1996). Sticks and stones and sugar and spice: Girls' and boys' aggression in schools. Australian Journal of Guidance \& Counseling, 6, 45-55.

Oyserman, D., Coon, H. M., \& Kemmelmeier, M. (2002). Rethinking individualism and collectivism: Evaluation of theoretical assumptions and meta-analyses. Psychological Bulletin, 128, 3-72.

Peterson, G. W., \& Hann, D. (1999). Socializing parents and children in families. In S. Steinmetz, M. Sussman, \& G. W. Peterson (Eds.), Handbook of marriage and the family (rev. ed., pp. 327-370). New York: Plenum Press.

Porter, C. L., Hart, C. H., Yang, C., Robinson, C. C., Olsen, S., Zeng, Q., et al. (in press). A comparative study of child temperament and parenting in Beijing, China and the Western United States. International Journal of Behavioral Development.

Profilet, S. M., \& Ladd, G. W. (1994). Do mothers' perceptions and concerns about preschoolers' peer competence predict their peer-management practices? Social Development, 3, 205-221.

Renshaw, P. D., \& Brown, P. J. (1993). Loneliness in middle childhood: Concurrent and longitudinal predictors. Child Development, 64, 1271-1284.

Rohner, R. P. (1975). They love me, they love me not. New Haven, CT: HRAF Press.

Rohner, R. P. (1986). The warmth dimension: Foundations of parental acceptancerejection. Thousand Oaks, CA: Sage.

Rubin, K. H. (1982). Nonsocial play in preschoolers: Necessarily evil? Child Development, 53, 651-657.

Rubin, K. H., Burgess, K. B. (2002). Parents of aggressive and withdrawn children. In M. H. Bornstein (Ed.), Handbook of parenting: Vol. 1. Children and parenting (2nd ed.; pp. 383-418). Mahwah, NJ: Lawrence Erlbaum Associates. 
Rubin, K. H., Burgess, K. B., \& Coplan, R. J. (2002). Social withdrawal and shyness. In P. K. Smith \& C. H. Hart (Eds.), Blackwell handbook of child social development (pp. 330-352). Malden, MA: Blackwell Publishers.

Rubin, K. H., Burgess, K. B., \& Hastings, P. D. (2002). Stability and social-behavioral consequences of toddlers' inhibited temperament and parenting behaviors. Child Development, 73, 483-495.

Rubin, K. H., Burgess, K. B., Kennedy, A. E., \& Stewart, S. L. (2003). Social withdrawal in childhood. In R. A. Barkley \& E. J. Mash (Eds.), Child psychopathology (2nd ed., pp. 372-406). New York: Guilford Press.

Rubin, K. H., Chen, X., \& Hymel, S. (1993). Socioemotional characteristics of withdrawn and aggressive children. Merrill-Palmer Quarterly, 39, 518-534.

Rubin, K. H., Chen, X., McDougall, P., Bowker, A., \& McKinnon, J. (1995). The Waterloo longitudinal Project: Predicting internalizing and externalizing problems in adolescence. Development and Psychopathology, 7, 751-764.

Rubin, K. H., Coplan, R. J., Fox, N. A., \& Calkins, S. D. (1995). Emotionality, emotion regulation, and preschoolers' social adaptation. Development and Psychopathology, 7, 49-62.

Rubin, K. H., \& Mills, R. S. L. (1990). Maternal beliefs abut adaptive and maladaptive social behaviors in normal, aggressive, and withdrawn preschoolers. Journal of Abnormal Child Psychology, 18, 419-435.

Rubin, K. H., Mills, R. S. L., \& Rose-Krasnor, L. (1989). Maternal beliefs and children's competence. In B. H. Schneider, G. Attili, J. Nadel, \& R. P. Weissberg (Eds). Social competence in developmental perspective (pp. 313-331). New York: Kluwer Academic/Plenum Publishers.

Rubin, K. H., Nelson, L. J., Hastings, P., \& Asendorpf, J. B. (1999). The transaction between parents' perceptions of their children's shyness and their parenting styles. International Journal of Behavioral Development, 23, 937-958.

Russell, A., Hart, C. H., Robinson, C. C., \& Olsen, S. F. (2003). Children's sociable and aggressive behavior with peers: A comparison of the U.S. and Australia, and contributions of temperament and parenting styles. International Journal of Behavioral Development, 27, 74-86.

Schaughency, E. A., Vannatta, K., Langhinrichsen, J., Lally, C. M., Seely, J. (1992). Correlates of sociometric status in school children in Buenos Aires. Journal of Abnormal Child Psychology, 20, 317-326.

Schneider, B. H., Attili, G., Vermigli, P., \& Younger, A. (1997). A comparison of middle class English-Canadian and Italian mothers' beliefs about children's peer-directed aggression and social withdrawal. International Journal of Behavioral Development, 21, 133-154.

Schoenhals, M. (1993). The paradox of power in the People's Republic of China middle school. Armonk, NY: M.E. Sharpe.

Schwartz, D., Chang, L., \& Farver, J. M. (2001). Correlates of victimization in Chinese children's peer groups. Developmental Psychology, 37, 520-532.

Sebanc, A. M. (2003). The friendship features of preschool children: Links with prosocial behavior and aggression. Social Development, 12, 249-268.

Steinberg, L., Darling, N. E., \& Fletcher, A. C. (1995). Authoritative parenting and adolescent adjustment: An ecological journey. In P. Moen, G. H. Elder Jr., \& K. Luescher (Eds.), Examining lives in context: Perspectives on the ecology of human development (pp. 423-466). Washington, DC: American Psychological Association. 
Tomada, G., \& Schneider, B. H. (1997). Relational aggression, gender, and peer acceptance: Invariance across culture, stability over time, and concordance among informants. Developmental Psychology, 33, 601-609.

Triandis, H. C. (1994). Culture and social behavior. New York: McGraw-Hill.

Triandis, H. C. (2000). Cross-cultural versus cultural psychology: A synthesis? In U. P. Gielen \& A. L. Comunian (Eds.), International perspectives on human development (pp. 81-95). Lengerich, Germany: Pabst Science.

Valdivia, I. A., Schneider, B. A., Chavez, K. L., \& Chen, X. (2005). Social withdrawal and maladjustment in a very group-oriented society. International Journal of Behavioral Development, 29, 219-228.

Vandenberg, R. J., \& Lance, C. E. (2000). A review and synthesis of the measurement invariance literature: Suggestions, practices, and recommendations for organizational research. Organizational Research Methods, 3, 4-69.

Wu, P., Robinson, C. C., Yang, C., Hart, C. H., Olsen, S. F., Porter, C. L., et al. (2002). Similarities and differences in mother's parenting of preschoolers in China and the United States. International Journal of Behavioral Development, 26, 481-491.

Xie, H., Swift, D. J., Cairns, B. D., \& Cairns, R. B. (2002). Aggressive behaviors in social interaction and developmental adaptation: A narrative analysis of interpersonal conflicts during early adolescence. Social Development, 11, 205-224.

Yang, C., Hart, C. H., Nelson, D. A., Porter, C. L., Olsen, S. F., Robinson, C. C., et al. (2004). Fathering in a Beijing, Chinese sample: Associations with boys' and girls' negative emotionality and aggression. In R. D. Day \& M. E. Lamb (Eds.), Conceptualizing and measuring father involvement (pp. 185-215). Mahwah, NJ: Lawrence Erlbaum Associates. 